\title{
On some Semantic Differences between Verbal Forms of the Past Tense in the Albanian Language
}

\author{
Alma Pinari (Kallari), PhD. \\ Tirana University \\ Faculty of Foreign Languages \\ Department of Slavic and Balkan Languages \\ Russian language Branch \\ E-mail: almapinari@gmail.com
}

\begin{abstract}
In the studies on Albanian verbal system, linguists do not share the same opinion about semantic differences among verbal forms of the past. In some juxtapositions of verbal forms of the past, linguists distinguish aspect meanings or nuances, which, according to them, characterize the action by its feature of finiteness / infiniteness. In the following article efforts argue the view that the distinction among forms of Albanian past has nothing to do with the aspect as a morphologic category, present in the Slavic languages. It elaborates the idea that the meanings or nuances acquired by forms of indicative past interacting with some context elements characterize not only realization of tense categorical meanings, but also several other meanings of aspectual but not aspect character. Aspectual phenomena (meanings) stand out in the functional level by interaction linguistic means of different levels.
\end{abstract}

Keywords: aspectual shades, aspectual meanings, aspectual context etc.

Semantic differences between verbal forms in the Albanian language, continue to attract the attention of many Albanian language's researchers. Actually this is quite understandable if we take into consideration the fact that the Albanian verbal system is characterized by a variety of tenses that are used not only in order to describe the time that an action takes place but also to show the manner that this action flows in a certain period of time. (Bondarko A.V.,1987).

According to many researchers, the case of verb tenses remains one of the most important topics of the Albanian language. However, it is worth mentioning that even for this topic, researchers share some different point of views regarding verbs and tenses in the Albanian language.

For instance, according to many studies the definition of potential semantic forms of time and the principle of differentiation from other meanings is still not very clear. Whenever we are dealing with past forms of the verbs we encounter a special confusion which is clearly associated with semantic components of meaning, time and its aspects.

In Albanian language more rich in grammatical forms, is the past tense (Demiraj Sh., 1985), with its subdivisions: past simple, present perfect, past perfect and other past tenses, so-called relative tenses. The three first, the so-called absolute time of the past, express pre-timing in relation to the time of speech and hence oppose each other in aspectual area (Grammar of the Albanian Language 1 (2002). While the last two the so-called relative tenses of the past, that express pretiming in relation to a particular moment of the past, do not have a clear semantic distinction between them. The semantic of the past tense is the semantic of precedence of the time of speech, which comes out in counterpoint with the present.

When it comes to the subdivision of the past tenses the Albanian language's theoretical grammar authors name them as tenses, which show the exact moment when we deliver the speech but on the other hand they are different in other aspects. (Grammar of the Albanian Language 1 (2002). Generally speaking with the terms of meaning and connotations we understand the reaction between the imperative and perfect aspect.

In this paper we will mainly focus on the contravention within the past tenses of indicative form, bringing some very important arguments regarding the difference between the meaning of time and other aspects obtained during the context. 
In his linguistic masterpiece professor Shaban Demiraj highlights the pure different aspect between imperfect and simple perfect. According to the author the simple perfect aims to emphasize the idea of a certain action which has already ended in a certain period of the past. Meanwhile the imperfect form of the verb deals with an action which was occurring during a specific moment in the past. (Demiraj, Sh., 1985),

On the other hand, regarding the contravention between past forms of verb such as e kryer/e kryer e thjeshte which are equivalent to the past simple and present perfect in the English language, the same author expresses the idea that these forms are more difficult to be explained. This happens because both these forms introduce the end of an action before the moment of speech. However, when we talk about past simple the action does not have a big connection with the moment of speech, while the action introduced in the present perfect does not disconnect with the moment of speech because of the consequences.

The author concludes with the idea that the past simple is characterized by the synthesis of an ended action in the past. But, in this aspect professor Demiraj has distinguished some other differences among other forms of past tenses such as past perfect and simple past perfect.

There are a lot of other linguistics which have dealt with past tenses in Albanian language (Dodi, A., 1968/1; Agalliu, F., 1968/2 etj.) , and they have all concluded in the idea that as a matter of fact, the difference between past tenses have nothing to do with the aspect of time, since in most of the past tenses the action has already occurred before the moment of speech. So, they all agree that the biggest difference between past tenses in Albanian language deals with the ingredient of aspect, so the context that we are talking about bring the meaning of time in past tenses.

For such a long period of time, the notion of 'aspect' in the Albanian language has dealt mainly with the idea of different form of the verbal action, which means for example; an action happening during the moment of speech, an action which continues in the future, an action which has been continuing in the past, an intensive action or not intensive etc.

For the very first time, the difference between the meaning of aspect and other aspect meaning which are closely related to the verb forms, was brought to discussion by professor Ali Dhrimo in his monograph regarding aspect and terms of the verb. This book was published in 1996, (Dhrimo, A. 1996).

For this reason it is not difficult to notice that there are many cases in which partial or total assertions about verbal aspects brought a huge confusion in the review of potential semantic verbal forms in the Albanian language. It is worth mentioning that the category of aspect in the Albanian language has not found yet a formal expression because it is not developed in the statue of a morphological category. On the other hand whenever we speak about the meaning of different verbal traits we encounter another contravention between the perfect and imperfect aspect of tenses. This attitude regarding the contravention semantic of past tenses seems to be completely implausible.

Another important aspect that deserves to be discussed is the fact that in the Albanian language the characteristics of the verbal actions has not been part of grammatical structures. According to many linguistics the meaning of 'past' in Albanian language is a morphological case. For instance when we take into consideration the difference between simple past / past continues the case of aspect is the core of the contravention between perfect and imperfect aspect.

The completed action in the past perfect tense can not be treated as a pure meaning of aspect. This is due to the fact that the finished action indicates at the same time one of the other stages of action development, unless we are dealing with another tense.

The Albanian language has no special tools to define the perfective of the verb action. The terms perfect / imperfect (past simple / present perfect) and perfective / imperfective (past aspect / present perfect aspect), although connected by the idea of time, they belong to different semantics.

The contravention past simple / present perfect can only be justified for action completed / ongoing action feature and only for that group of verbs that express proper completed action. This opposition remains partial, incomprehensive. Thus, besides this contravention there remain other uses of the past simple such as repetition of the action in the past meaning, ordinary action meaning, the past action meaning etc. The contravention is isolated from cases as discussed above, when the past simple of Albanian language expresses not only unfinished actions, but aw well completed actions (He called us every evening at home. She sent a few messages a day).

From this perspective it can be argued that the contravention completed action / uncompleted action to the simplest forms of the past tense cannot be seen as pure aspectual meaning for several reasons: 
Firstly, not all verbs in the past simple express a completed action. The completed action meaning is mainly due to the verbs that are followed by an object, including the action of the verb.

Secondly, the outcome of the action is just one of its stages, while the other stages of its development remain out of sight of the speaker'. Furthermore, in this stage of the action the boundary between aspectual semantics and temporal semantics of the completed action concept is deleted.

hirdly, completed action can show the forms of the imperfect (During the day she drank some cups of coffee. He sent me several messages a day). In these examples the imperfective verbs (drank, sent) show action with several acts, each act completed separately. These linguistic facts lead us to conclude that, while the same feature is present in aoristic past, as well in the imperfective past, counting on it becomes invalid to claim that the Albanian contravention completed action / uncompleted action is an aspectual contravention (in terms of grammatical aspect contravention perfective / imperfective aspect in Slavic languages).

Fourth, for several decades linguists specialized in aspectual meaning do not consider the contravention completed action / uncompleted action as semantic feature underlying the morphological category of aspect. Along with other stages (initiation and continuation of an action) the meaning of completion of the action, or otherwise known as aspectual terminative understanding, belongs to the ways of conduct and not the category of aspect.

Finally, there is also an indirect argument proving that the contravention past simple / present perfect of the Albanian language, regarding the semantic content is not identical to the contravention completed aspect / uncompleted aspect of the languages that have the morphological category of aspect. In favor of this opinion speaks the presence of these two types of contravention in Macedonian Bulgarian language. These languages have also conducted aorist aspect, aorist and imperfect aspect, the imperfective completed aspect, even imperfective uncompleted aspect. The presence of the two contraventions in the Slavic languages speaks to their different semantics.

Compared with the Russian language (Bondarko, AV, Bullanin, LI. LI. 1967), it can be stated that the present perfect of the Albanian language coincides with one of the uses of the past completed aspects of the Russian language, using its aoristic, but no grammatical meaning of the verb completed aspect in this language. The same can be said for the past simple, which coincides with the past forms of the imperfect aspect, when they are used in the sense of the imperfect.

Different from the contravention past simple / present perfect, the contravention completed aspect / uncompleted aspect includes verb in its entire paradigm. It is indifferent to the instant of the speech (compare, for example, continuing forms of verbs type открыть / открывать, which does not have the category of time, but belong to the completed or uncompleted aspect). Rather, the meaning of the contravention past simple / present perfect in Albanian language does not exceed this threshold; it is bordered by it and remains within the schedule of the past.

We think that regarding the Albanian language it would be more fair to talk not about perfective / imperfective aspect, rather about aspectual meanings (Bondarko AV, 1987) by which we understand the features of continuity, duration, intensity, completion, repeating the action, etc. which are realized by the temporal forms in conjunction with the vocabulary and context. Implementation of the above meanings or nuances, different from the categorical meaning of time, is related to the aspectual semantic area, thus the manner of the course of action in time.

Obviously, different meanings or nuances derived from the interaction of the grammatical form, the context or a particular lexical class should be taken into consideration, but that does not mean that they should be included in the grammatical form. It should be well differentiated the understanding of the shape itself from other meanings realized in different contexts.

Regarding the forms of the perfective, they encourage the speaker to bring in mind a situation that has happened before, immediately before the speech. In this sense the perfective involves a clear temporal semantics. But the forms of the perfective do not only state the fact happened in the past, they convey something more than that. The past gives original information that connects the latter with a moment that comes after, which can be in such a proportion as cause and effect, etc. This composite form expresses the "value" that the past action has in the present. This is not observed in present perfect. This form presents the fact that is communicated differently: as a given fact without the mediation of any other thing, without any particular characteristic. Such a distinction is confirmed as well by the ability these shapes have to intertwine with the time situational objects. Usually the present perfect is used in accordance with the lexical indicators such as yesterday, last year, 1980 etc., which express specific time of completion of the action. These indicators are not characteristic forms of the present perfect. 
The past simple is usually used with rare situational objects such as often, sometimes etc. The differences observed in the combining skills of the above forms, should be considered closely related to their grammatical meaning.

The claim that the past simple time forms are characterized by "mixed aspect" seems implausible, for the reason that a verbal form used in sentences cannot express simultaneously the perfective and imperfective meaning aspect. Interpreting the past perfect of the Albanian language we forget for a moment that it called past perfect not in the temporal meaning (as past simple and present perfect it is a past tense), but because of its ties with the present through the consequences of the outcome of the action. It's exactly this feature that creates what we call the past perfective meaning, different from the imperfective and aoristic meaning. Then, why should we invent aspectual contravention within the same form, or undue terms from linguistic facts such as mixed aspect? The presence of the "product" of an action in the past into the present does not form aspectual contravention such as perfect/imperfect aspect.

The past perfect of the Albanian language can also express an action that ended in the past, but the concrete result of action is not present at the time of speech. Even in this case it cannot be claimed that the form of the past perfect has the perfective aspect meaning, for example : He has built art monuments (meaning: he knows, is able to do something like that).

The form of the past in the above context expresses an action (several times) to characterize the subject at a given moment. If you would translate this sentence in Russian language along with morphological aspect category, the perfect form of Albanian language verb "has built" would be given the shape of the Russian imperfective: Он строил памятники искусства.

Depending on the lexicon and grammatical features of verbs and the context of past simple, the present perfect and past perfect forms, besides the meaning of past time in relation to the time of the speech, during their function, they have the ability to modify their meanings.

All these past verb action features are aspectual components, which in relation to the past temporal component can be called secondary, irrelevant.

Regarding the presence of several meanings, the so-called aspectual, implemented in certain contexts, we think they are not related to contravention perfective aspect / imperfective aspect. The realization of these other meanings or nuances, different from the categorical meaning of time, is related to semantic wider areas than the morphological category. Grammatical category of time for instance, is the main component for the expression of temporal semantics (Pinari (Kallari) A., 2014)., nevertheless not the only one. Other lexical means also express certain temporal relations time of this field of semantics, but in relation to morphological category, they are its peripheral elements.

Regarding the Albanian language, we think it would be fair to talk not about perfective / imperfective aspect, because as noted above, it lacks formal tools of the perfective and imperfective. For us the difference between the past forms is aspectual (Pinari (Kallari) A., 2014). And with the aspectual meaning we understand the outcome of the action, the stage of starting or continuing, but also other features like repeating verbal action, intensity, quantitative escalation, sustainability etc.

Aspectual, temporal meanings, but as well of other semantic areas are realized not only by morphological contravention, as well by means of different language levels (Bondarko AV, 1987). Aspectual semantics of the Albanian language finds expression at the semantic-functional level and depend on interaction time paradigms and context or aspectual situations,, but in any case without reference to the moment of speech.

As noted, confusion or difficulty in differentiating past tense forms meanings is based on the observation of these meanings within the framework of morphological categories, by omitting the interaction of other components of the semantic - functional areas of concern?

\section{References}

[1] Agalliu, F. (1968) "Critical observations on the meanings of some tenses". Philological studies 1968/2, P.135.

[2] Bondarko, A. V., Bullanin, LI. LI. (1967) "Russkij gllagoll”, Leningrad. P.50;

[3] Bondarko, A.V. (1975), "O Vidah russkogo gllagolla", Russkij Jazik za rubjezhom, № 5, Moskva, P. 63-65;.

[4] Bondarko A.V. (1987) Teoria funksionalnoy grammatiki. Vvjedenie V Aspektualnost'. Vremenaya llokalizovanost". Taksis. Leningrad. 
[5] Comrie, B. (1976), Aspect An Introduction to the Study of Verbal Aspect and Related Problems, Cambridge: Cambridge univ. Press.

[6] Dodi, A. (1968) "About the use of perfect tenses", Philological studies, 1968/1.

[7] Demiraj, Sh. (1985) "Historical Grammar of the Albanian Language", Tirana, P.713-715, 716, 722, 740.

[8] Demiraj, Sh. (1971) "The main recent Meanings of the indicative form", Philological studies, 1971/4.

[9] Dhrimo, A. (1996), "Aspect and the verbal modes of tense actions in Albanian language", Publishing House "University Book", Tirana, P. 61, 70, 151-152.

[10] Grammar of the Albanian Language 1 (2002), Academy of Sciences of Albania, Institute of Linguistics and Literature, Tirana, P. 274.

[11] Masllov, J.S. (2004), Izbranije trudi, Aspektollogija, Obshee jazikoznanie, Jaziki Sllavjanskoj Kulturi, Moskva.

[12] Pinari (Kallari) A. (2014) "Linguistic categorization of temporal tenses in the Albanian language compared to the Russian language". PhD, work Tirana. 